\title{
O impacto da corrupção arbitrária e generalizada nos influxos de IDE e o efeito moderador da distância de corrupção: Evidências da América Latina
}

\author{
Daniel Mendes Pessegueiro ${ }^{1 A B}$, Manuel Aníbal Silva Portugal Vasconcelos Ferreira ${ }^{A B C}$ \\ Nuno Rosa Reis ${ }^{A B}$ e Cláudia Sofia Frias Pinto ${ }^{C}$ \\ ${ }^{A}$ Escola Superior de Tecnologia e Gestão, Instituto Politécnico de Leiria, ESTG-IPL, Leiria, Portugal \\ ${ }^{B}$ Centre of Applied Research in Management and Economics, CARME, Leiria, Portugal \\ 'Universidade Nove de Julho, PPGA, UNINOVE, São Paulo, SP, Brasil \\ DUniversidade do Oeste de Santa Catarina, PPGA, UNOESC, Chapecó, SC, Brasil
}

\section{DETALHES DO ARTIGO}

\section{Histórico do Artigo:}

Recebido: 08 de Agosto de 2017

Revisado: 11 de Setembro de 2017

Aceito: 07 de Dezembro de 2017

Disponível online: 10 de Abril de 2018

Sistema de revisão "Double blind review"

Editor Científico

Raquel Moutinho

\section{Palavras-chaves:}

Corrupção arbitrária

Corrupção generalizada

Distância da corrupção

Investimento direto estrangeiro

América Latina.
RESUMO

\begin{abstract}
Não é consensual na literatura a prevalência de um efeito negativo da corrupção sobre a capacidade de atração de investimento direto estrangeiro (IDE). Alguns países têm, simultaneamente, altos níveis de corrupção e de influxos de IDE. Neste estudo distinguimos o efeito de dois tipos de corrupção - arbitrária e generalizada - e o papel moderador da distância da corrupção entre o país investidor e receptor na capacidade de atração de IDE. Num estudo empírico dos influxos de IDE para países da América Latina, os resultados mostram que a corrupção generalizada reduz a atratividade ao investimento estrangeiro e que a distância de corrupção ameniza o efeito negativo da relação entre corrupção arbitrária do país receptor e os influxos de IDE. Este estudo contribui para aprofundar a pesquisa sobre os efeitos da corrupção, em particular quanto ao efeito diferenciado dos tipos de corrupção e dos efeitos da distância de corrupção nos influxos de IDE.
\end{abstract}

(C) 2018 Internext | ESPM. Todos os direitos reservados!

\section{INTRODUÇÃO}

A influência da corrupção na capacidade de os países atraírem investimento direto estrangeiro (IDE) é extensamente analisada na literatura porém com resultados inconclusivos (Habib \& Zurawicki, 2002; Cuervo-Cazurra, 2006, 2008; Godinez \& Liu, 2015; Ferreira et al., 2016). A corrente dominante argumenta que a corrupção tem um impacto negativo na capacidade de atrair IDE ao aumentar a incerteza e os custos do IDE (Smarzynska \& Wei, 2000; Wei, 1998, 2000; Habib \& Zurawicki, 2002; Voyer \& Beamish, 2004; Egger \& Winner, 2005). Contudo, outra corrente argumenta que a corrupção facilita o IDE ao olear as transações, que se tornam mais expeditas, e ao ultrapassar as ineficiências institucionais (Huntington, 1968; Bardhan, 1997; Cuervo-Cazurra, 2008). Os benefícios de contornar instituições ineficientes através da corrupção podem compensar os custos adicionais e a incerteza (CuervoCazurra, 2008). Ainda outros autores não encontraram relação entre corrupção e IDE (ex., Hines, 1995). No entanto, apesar de a literatura relativa à influência da corrupção no IDE ser vasta, tem descurado duas dimensões: por um lado, distinguindo o tipo de corrupção (exceções em Rodriguez et al., 2005; Cuervo-Cazurra, 2006; Ferreira et al., 2016) e, por outro lado, ainda menos frequentemente considerando a distância de corrupção entre países investidores e receptores de IDE (Habib \& Zurawicki, 2002; Godinez \& Liu, 2015). 
A corrupção, enquanto elemento da qualidade institucional dos países, é um indicador na capacidade de atração de IDE (Kinoshita \& Campos, 2004; Egger \& Winner, 2005; Wernick et al., 2009; Zeghni \& Fabry, 2009). Ambientes institucionais mais desenvolvidos, e por conseguinte com menores níveis de corrução, possivelmente incentivam o IDE ao reduzir os ricos, incertezas e custos de transação (Ali et al., 2010; Chao \& Kumar, 2010). Insuficiências institucionais como a falta de monitorização dos sistemas legais (Lapalombara, 1994; Jeong \& Weiner, 2012) ou a existência de burocracia excessiva ou ineficiente (Leff, 1964; LaPalombara, 1994; CuervoCazurra, 2006) promovem a recorrência de comportamentos de abuso de poder público para a obtenção de benefícios privados.

$\mathrm{Na}$ internacionalização, quanto maiores forem as diferenças dos níveis de corrupção, menor é a probabilidade de as empresas multinacionais (EMNs) saberem lidar com as pressões sociais, e menor será a probabilidade de realizarem IDE (Habib \& Zurawicki, 2002). No entanto, alguns estudos demonstram que é a distância de corrupção, e talvez o seu sentido, que diferencia o impacto da corrupção no IDE. Godinez e Liu (2015), por exemplo, evidenciaram que as EMNs sedeadas em países com níveis de corrupção relativamente baixos não estão familiarizadas com as instituições formais e informais associadas à corrupção, percepcionando maior risco e maior incerteza no IDE. Por outro lado, as empresas sedeadas em países com elevados níveis de corrupção não são dissuadidas por alta corrupção nos países receptores de IDE. Ou seja, por um lado, há a possibilidade de as EMNs provenientes de países pouco corruptos enfrentarem dificuldades no entendimento dos valores e normas do mercado onde irão atuar, assim como a legitimidade organizacional que devem alcançar perante fenómenos de corrupção. Por outro lado, as EMNs provenientes de países corruptos poderão ter outra sensibilidade perante a corrupção, visto poderem ter desenvolvido capacidades para lidar com a mesma nos seus países de origem (Godinez \& Liu, 2015; Ferreira et al., 2016).

Neste estudo analisamos a influência da corrupção arbitrária e corrupção generalizada nos influxos de IDE, verificando o papel moderador da distância da corrupção entre o país investidor e o país receptor do IDE. Especificamente, avaliamos se a relação entre a corrupção arbitrária e generalizada e os influxos de IDE é alterada, dependendo da distância entre os níveis de corrupção dos países investidores e os níveis de corrupção dos países receptores de IDE. Empiricamente, observamos os influxos de IDE em países da América Latina, entre 2010 e 2014. Com uma amostra de 473 investimentos provenientes de 27 países em 17 países da América Latina, utilizámos modelos de regressão Tobit. Concluímos que a corrupção generalizada tem um impacto negativo nos influxos de IDE e que a distância de corrupção modera o efeito da corrupção arbitrária nos influxos e IDE.

Este estudo tem duas contribuições. Primeiro, estende o conhecimento existente sobre o impacto da corrupção do país receptor na sua capacidade de atrair IDE. Face aos resultados contraditórios de outros estudos, justificam-se demonstrações empíricas adicionais sobre a capacidade desincentivadora ou estimuladora da corrupção sobre o IDE. Os países da América Latina proporcionam o contexto para o teste empírico. Mas, especialmente, esta extensão abrange a análise do tipo de corrupção nos influxos de IDE. Corrupção arbitrária e corrupção generalizada implicam diferentes configurações com, previsivelmente, influências distintas sobre os fluxos de IDE (CuervoCazurra, 2008).

Segundo, contribui para a ainda incipiente pesquisa sobre o papel moderador da distância da corrupção entre o país investidor e o país receptor de IDE, sublinhando a importância da qualidade institucional do país investidor no contexto do investimento estrangeiro. A distância da corrupção tem sido vista como dissuasora do IDE na medida em que as diferenças institucionais aumentam o esforço das multinacionais na recolha, interpretação e organização da informação necessária para o IDE (Godinez \& Liu, 2015). Porém, o sentido em que flui o investimento é determinante, devido a possíveis competências adquiridas pelas multinacionais, com base na experiência em lidar com a corrupção nos seus ambientes domésticos.

\section{REVISÃO DA LITERATURA E HIPÓTESES}

O aumento do volume de IDE a partir da década de 90 despertou um interesse acrescido na comunidade académica sobre os possíveis determinantes dos fluxos de IDE (Daude \& Stein, 2007; Ali, Fiess \& Macdonald, 2010). Os fatores económicos têm sido tradicionalmente vistos como os determinantes fundamentais dos fluxos de IDE (Mudambi \& Navarra, 
2002), incluindo aspetos como a dimensão e crescimento do mercado, o acesso a recursos naturais, o custo da mão-de-obra, o nível de inflação, entre outros (Habib \& Zurawicki, 2002). No entanto, as diferenças nas estruturas institucionais dos países eram ou ignoradas ou tidas como um fator secundário (Mudambi \& Navarra, 2002). Contudo, as instituições são elementos críticos nas decisões de IDE das empresas, e ambientes institucionais desenvolvidos atraem IDE por reduzirem os custos de transação (Mudambi \& Navarra, 2002; Gelbuda et al., 2008). A qualidade institucional dos países são fundacionais para a sua capacidade de atrair IDE (Bevan et al., 2004; Bénassy-Quéré et al., 2007; Wernick et al., 2009). A qualidade institucional abrange elementos tão distintos como a estabilidade do governo, ausência de tensões sociais, cumprimento da lei, desenvolvimento econômico, sofisticação da educação, incorporação de conhecimento, etc. (Peng \& Heath, 1996; Peng, 2003; Ferreira et al., 2016).

A corrupção é uma face de ambientes institucionalmente menos desenvolvidos. A corrupção prejudica o desempenho das empresas (Doh et al., 2003; Uhlenbruck et al., 2006; CuervoCazurra, 2008). A corrupção pode ser o resultado de insuficiências institucionais (Ferreira et al., 2016). Um exemplo comum de como as lacunas institucionais originam corrupção é a falha dos sistemas judiciais na monitorização das leis, cumprimento das mesmas e sancionando as infrações (Karnani, 2007). A falta de monitorização e um sistema institucional deficitário incentivam a corrupção (Jeong \& Weiner, 2012). Em contrapartida, instituições políticas e legais sofisticadas atuam como barreiras à corrupção, formalizando os custos associados à corrupção sob a forma de multas (Galang, 2012), e processos judiciais. Então, se quadros institucionalmente sofisticados permitem atrair EMNs e investimento, a existência de vazios e ineficiências institucionais retrai as empresas de investir.

Apesar do argumento e convicção corrente que a corrupção é prejudicial ao desenvolvimento, o efeito da corrupção na atração de IDE não é claro. Estereotipicamente, países com altos níveis de corrupção tendem a atrair menos IDE (Wei, 1998). Isto porque os países corruptos não oferecem as mesmas condições de acesso aos mercados a todos os concorrentes, favorecendo aqueles que pagam subornos (Wei, 1998). No entanto, uma outra perspectiva propõe que a corrupção é facilitadora dos negócios, tornando as transações mais expeditas, ao ultrapassar as deficiências institucionais (Bardhan, 1997; Huntington, 1968). Nestes casos, a corrupção pode, efetivamente, facilitar a realização de IDE (Cuervo-Cazurra, 2008). Por exemplo, o suborno a agentes civis com vista à obtenção de licenciamentos despoleta mecanismos de mercado e incentivos a um melhor funcionamento dos sistemas burocráticos (Lui, 1985). Ou seja, a corrupção pode constituir uma vantagem contra os riscos do sistema político, na medida em que ajuda a mitigar riscos tais como o da expropriação (Leff, 1964). Então, um efeito positivo da corrupção na atração de IDE ocorrerá sobretudo em países com instituições menos desenvolvidas, e com regulamentação excessiva ou ineficiente (Cuervo-Cazurra, 2006; Leff, 1964). Em países com excesso de regulamentação e de outros controlos administrativos, a corrupção pode agir como uma "mão amiga" para incentivar o IDE (Egger \& Winner, 2005). Em suma, os benefícios de contornar instituições deficientes através da corrupção podem compensar os custos e incertezas adicionais.

\subsection{Corrupção arbitrária e generalizada do país receptor e os influxos de IDE}

A corrupção pode ser distinguida em dois tipos: arbitrária e generalizada. A corrupção arbitrária refere-se à incerteza associada aos atos de corrupção (Rodriguez et al., 2005; Cuervo-Cazurra, 2008), por contraponto à corrupção generalizada que reflete o grau de institucionalização da corrupção, isto é, a sua transversalidade no sector público (Rodriguez et al., 2005) ou mesmo na sociedade. A corrupção arbitrária representa a incerteza associada à corrupção. As EMNs, ao entrarem em mercados estrangeiros com corrupção arbitrária, não sabem se lhes serão ou não solicitados subornos para o alcance dos objetivos, nomeadamente contratos públicos ou licenciamentos, entre outros (Cuervo-Cazurra, 2008). Wei (1998) demonstrou que as incertezas relacionadas com a corrupção têm maior influência na capacidade de atrair IDE do que o nível de corrupção, analisados separadamente. De facto, a dificuldade de as EMNs cumprirem os requisitos das leis, normas e regulamentos será tanto maior quanto maior a corrupção arbitrária nos países receptores do investimento (Rodriguez et al., 2005).

A corrupção arbitrária no país de destino terá um efeito negativo na decisão de realizar IDE. A corrupção arbitrária impede que as multinacionais 
consigam estimar, por exemplo, a probabilidade de Ihes serem solicitados subornos ou o custo desses subornos. Também existe possibilidade de diferentes elementos dos agentes políticos, judiciais e agentes burocráticos solicitarem subornos, independentemente uns dos outros (Cuervo-Cazurra, 2008). A corrupção arbitrária aumenta, assim, a dificuldade em planear os custos exatos de uma nova operação de IDE no estrangeiro (Rodriguez et al., 2005). Por isso, a corrupção arbitrária é vulgarmente perspectivada como corrupção desorganizada (Shleifer \& Vishny, 1993) devido à incerteza quanto à possibilidade de haver suborno e qual o tipo de suborno, pela possibilidade de independência de subornos, e pela incerteza quanto ao resultado efetivo do suborno (Doh et al., 2003; Rodriguez et al., 2005). Quanto menor for a corrupção arbitrária menores serão as incertezas associadas à operação e, portanto, será favorecida a decisão de investir nesse território (Wei, 1998).

Hipótese 1: Maior nível de corrupção arbitrária no país receptor está negativamente relacionado com a capacidade de atrair IDE.

A corrupção generalizada, em contraponto, pode ser entendida como o custo conhecido da corrupção. Ou seja, o custo expectável e previsível para que determinada operação, ou transação, ocorra (Cuervo-Cazurra, 2008). Este tipo de corrupção assenta na ideia de que o suborno que é pago assegura a entrega dos bens, ou a efetivação da transação acordada, daí também ser designado de corrupção organizada (Elliot, 1997).

Ao investirem em países com alta corrupção generalizada as empresas já têm a expectativa que terão de pagar quer seja a agentes públicos que lidam com os processos administrativos, para diminuir o fardo da burocracia, quer seja a agentes do governo, de forma a obter contratos públicos e licenciamentos (Cuervo-Cazurra, 2008). Em todo o caso, estes são custos e encargos que podem ser esperados e estimados antecipadamente. Assim, entendemos a corrupção generalizada como uma medida das pressões institucionais exteriores exercidas sobre as empresas para praticarem atos de corrupção (Uhlenbruck et al., 2006). Apesar de a corrupção generalizada refletir o custo conhecido da corrupção (Cuervo-Cazurra, 2008), os pagamentos recorrentes aumentam os custos (Meyer, 2001) e diminuem o retorno expectável do investimento das EMNs, desincentivando a realização de investimento estrangeiro.

Hipótese 2: Maior nível de corrupção generalizada no país receptor está negativamente relacionado com a capacidade de atrair IDE.

\subsection{A distância de corrupção}

As diferenças institucionais entre países aumentam as dificuldades das EMNs na recolha, interpretação e organização da informação necessária para o IDE. Estas diferenças desencorajam o IDE e podem inclusive emergir conflitos entre a necessidade de adaptação local e a própria estrutura interna da EMNs (Bénassy-Quéré et al., 2007). Também as diferenças entre os níveis de corrupção dos países de origem e de destino do IDE podem aumentar os riscos e custos do IDE. Conceitualmente, podemos referir estas diferenças entre países como distância. O conceito de distância já foi usado para referir a forma como as culturas diferem entre países (por exemplo, Kogut \& Singh, 1988) e como as instituições diferem (Hernández \& Nieto, 2015). Referimos aqui, a distância de corrupção como a diferença entre o nível de corrupção no sector público entre os países investidores e os países receptores do IDE, seguindo a proposta de Eden e Miller (2004).

Características específicas dos países investidores também influenciam o custo e a propensão de as EMNs enveredarem por práticas corruptas (Godinez \& Liu, 2015). O nível de corrupção dos países investidores determina, pelo menos em parte, a sensibilidade das EMNs perante a corrupção existente nos países receptores (Cuervo-Cazurra, 2006). Por exemplo, EMNs sedeadas em países com leis contra a corrupção no estrangeiro possivelmente tenderão a evitar investimentos em países com elevados níveis de corrupção, enquanto EMNs sedeadas em países corruptos não ficarão constrangidas em investir em países com níveis de corrupção similares (Cuervo-Cazurra, 2006). De modo idêntico, EMNs localizadas em países com baixos níveis de corrupção provavelmente evitarão investir em países com altos índices de corrupção (Habib \& Zurawicki, 2001), devido ao seu conhecimento limitado de como lidar com a corrupção. Nestes casos as empresas não aprenderam a lidar com a corrupção nos seus mercados domésticos (Pajunen, 2008), tornando a corrupção num fenómeno pouco familiar e dissuasor de investimento (Driffield et al., 2013). Isto é, as 
empresas sedeadas em países menos corruptos não desenvolveram uma corruption capability (Ferreira et al., 2016).

Se as diferenças institucionais e diferentes níveis de corrupção entre país investidor e país receptor de investimento desencorajam o IDE, é relevante entender se há efeitos adicionais da distância de corrupção entre países. Os países podem ser caracterizados por níveis elevados de corrupção arbitrária, um fenómeno que gera elevada incerteza (Ferreira et al., 2016). Portanto, a corrupção arbitrária por si só é dissuasora do investimento (Cuervo-Cazurra, 2008), não sendo expectável acréscimos de incerteza pelo facto de haver uma maior distância de corrupção. A corrupção arbitrária é, por exemplo, a corrupção de membros do governo e outras elites políticas, de juízes e burocratas que utilizam o seu poder de discricionariedade $e$ exploram os vazios legais. Estas formas de corrupção não parecem ter impacto na decisão de investimento porque os investidores estrangeiros estão conscientes do problema, mesmo que não o consigam mensurar. Ou seja, o acréscimo de incerteza e risco que poderia ser previsível pela maior distância de corrupção efetivamente não gera um decréscimo adicional do investimento. Efetivamente, as empresas de países mais corruptos podem até ter uma vantagem nas operações em outros países de alta corrupção na medida que podem ter o conhecimento de como lidar com as dimensões arbitrárias da corrupção.

Em suma, se o nível de incerteza associado à existência de corrupção arbitrária, acrescido pela incerteza criada pela potencial natureza emergente ou em transição dos mercados, não for suficiente para dissuadir o investimento, não é esperado que a distância a nível da corrupção potencie esse efeito dissuasor e, pelo contrário, atenue possível efeito negativo da corrupção arbitrária. Uma das explicações é avançada por Godinez e Liu (2015) que em condições de maior incerteza originada as empresas tenderão a usar modos de entrada que lhe permitam maior controlo sobre as operações no estrangeiro - e estes modos implicam em maiores investimentos.

Hipótese 3: A distância de corrupção entre o país investidor e receptor atenua a relação negativa entre a corrupção arbitrária e o influxo de IDE.

Como referimos, a corrupção generalizada está institucionalizada em um conjunto de práticas e normas que requerem adequação aos costumes, inclusive no que se refere a atos de suborno (Uhlenbruck et al., 2006). Existe, portanto, uma necessidade de as EMNs incorrerem em custos para adaptar às práticas informais de corrupção (Egger \& Winner, 2005). No entanto, a adaptação às normas e práticas requer competências e conhecimentos específicos sobre o país receptor (Cuervo-Cazurra, 2008). Contudo, o conhecimento será menor em condições de maior distância de corrupção e as EMNs terão menor capacidade de lidar com as pressões para operarem num domínio corrupto (Uhlenbruck et al., 2006). Os investidores que pretendam operar em países com corrupção generalizada e onde enfrentem níveis elevados de distância da corrupção incorrerão em maiores custos e riscos nas suas operações. Assim, a maior distância de corrupção reduz a capacidade de adaptação por parte das EMNs às normas e práticas do país receptor de IDE, reduzindo a probabilidade de investimento.

Hipótese 4: A distância de corrupção entre o país investidor e o receptor intensifica a relação negativa entre a corrupção generalizada e o influxo de IDE.

\section{MÉTODO}

A corrupção na América Latina tem sido considerada como profunda e enraizada (Godinez \& Liu, 2015). Apesar de alta corrupção, níveis significativos de IDE têm sido realizados na região e a proveniência desses investimentos é diversificada, predominando os investimentos com origem em países com níveis de corrupção relativamente menores - o que significa países mais desenvolvidos. Os influxos de IDE na América Latina têm aumentado não apenas pela atratividade do mercado (com uma dotação populacional de mais de 600 milhões e, ainda que com diferentes evoluções, uma classe média crescente) mas, também, porque os países da América Latina têm vindo a atravessar um período de transformações pró-mercado (Cuervo-Cazurra \& Dau, 2009). Ou seja, têm verificado uma melhoria do seu sistema institucional, com maior formalização e eficiência. Ainda assim, persistem, não apenas uma grande heterogeneidade entre os países Latino Americanos, como também persistem diferentes níveis de desenvolvimento econômico e institucional.

\subsection{Amostra}

A amostra utilizada neste estudo inclui influxos de IDE em 17 países da América Latina, entre 2010 e 2014, 
provenientes de 27 países investidores. Os países receptores de IDE considerados são: Argentina, Bolívia, Brasil, Chile, Colômbia, Costa Rica, República Dominicana, Equador, El Salvador, Guatemala, Honduras, México, Nicarágua, Panamá, Paraguai, Trinidad e Tobago e Uruguai. Os países investidores são: África do Sul, Alemanha, Argentina, Bélgica, Bermuda, Brasil, Canadá, China, Colômbia, França, Espanha, EUA, Guatemala, Holanda, Índia, Itália, Japão, Luxemburgo, México, Noruega, Panamá, Peru, Reino Unido, Rússia, Suíça, Uruguai e Venezuela. Apesar de o número de países receptores ser limitado, o número de observações totalizou 473 pares de países receptores/investidores de IDE. Destas 473 observações, 405 são de influxos de IDE de países menos corruptos para países mais corruptos e 68 são de influxos de IDE de países mais corruptos para menos corruptos.

\subsection{Variáveis}

A variável dependente do nosso estudo é o logaritmo natural do valor dos influxos de IDE, medidos em milhões de dólares, adicionando uma unidade, de modo a considerar os casos em que o influxo líquido reportado era igual a zero. Foram utilizados os influxos líquidos de IDE nos países da América Latina, entre 2010 e 2014. Estes influxos foram obtidos na publicação da Commission for Latin America and the Caribbean (ECLAC), de 2016.

As duas variáveis independentes incluídas no nosso estudo são a corrupção arbitrária no país receptor de IDE e a corrupção generalizada. A mensuração da variável de corrupção arbitrária no país receptor de IDE foi feita utilizando o desvio padrão do índice de percepção da corrupção (IPC), da Transparência Internacional. O desvio padrão deste indicador representa a variação nas pontuações atribuídas num determinado país. Esta variação reflete a incerteza sobre a percepção do nível de corrupção, servindo como proxy para a arbitrariedade (cfr. Ferreira et al., 2016; Bogmans \& Jong, 2011).

A corrupção generalizada foi operacionalizada com a medida proposta por Uhlenbruck et al. (2006) usando dados do Executive Opinion Survey, do World Economic Forum, disponíveis nos relatórios Global Competitiveness Report, entre os anos de 2010 e 2015. Esta medida é aferida com base na média das respostas aos cinco componentes da seguinte pergunta: "No seu país, é frequente as empresas terem que fazer pagamentos adicionais não documentados ou subornos relativos a (a) importações e exportações; (b) serviços de utilidade pública; (c) pagamento de impostos; (d) atribuição de contratos públicos e licenças; (e) obtenção de favorecimentos judiciais?" (nossa tradução). Apesar de no relatório original a escala das respostas variar de 1 (muito frequente) a 7 (nunca ocorrem), neste estudo invertemos a escala para melhor interpretação, de modo que valores mais baixos significam menor probabilidade de pedidos de suborno.

A distância de corrupção entre o país de origem e o país receptor é a diferença entre o valor do Índice de Percepção da Corrupção (IPC) do país investidor e o valor IPC do país receptor do investimento, usando dados da Transparência Internacional. Uma medida semelhante foi utilizada por Hernández e Nieto (2015), mas aplicada à distância institucional.

\section{Variáveis de controle}

Também incluímos um conjunto de variáveis de controle ao nível do país. Estas variáveis são geralmente consideradas em modelos gravitacionais, que têm demonstrado a sua utilidade na explicação dos fluxos de IDE (Wei, 2000; Bevan et al., 2004; Cuervo-Cazurra, 2008). A burocracia do país receptor de IDE é um reflexo de insuficiências institucionais, já que o excesso de burocracia funciona como um obstáculo ao IDE (Bénassy-Quéré et al., 2007; Godinez \& Liu, 2015). A burocracia do país receptor de IDE foi medida utilizando o valor, em dias, do tempo necessário para criar um novo negócio, com dados coletados de Doing Business Project, do Banco Mundial, disponíveis no Global Competitiveness Report.

A distância geográfica entre o país investidor e o país receptor de IDE será uma medida facilitadora do IDE, já que quanto maior for a distância, maiores os custos de transporte e por isso maior o incentivo ao IDE (Wei, 2000). Neste estudo, utilizámos a distância física, em quilómetros, entre as capitais dos pares de países investidores e receptores de IDE (cfr. Ferreira et al., 2016), disponíveis na base de dados Geodist, do Centre d'Etudes Prospectives et d'Informations Internationales (CEPII).

O Produto Interno Bruto (PIB) do país receptor de IDE indica a dimensão do mercado e sua atratividade (Globerman \& Shapiro, 2003; Buckley et al., 2007). Neste estudo, utilizamos o logaritmo natural do PIB 
Tab. 1

Descrição das variáveis

\begin{tabular}{|c|c|c|}
\hline Variável & Mensuração & Fonte \\
\hline Influxo de IDE & $\begin{array}{l}\text { Logaritmo natural dos influxos de IDE no país receptor, em milhões de } \\
\text { dólares }\end{array}$ & $\begin{array}{l}\text { Commission for Latin America and the } \\
\text { Caribbean (ECLAC, 2016) }\end{array}$ \\
\hline \multicolumn{3}{|c|}{ Variáveis Independentes } \\
\hline $\begin{array}{l}\text { Corrupção arbitrária do país } \\
\text { receptor de investimento }\end{array}$ & Desvio padrão do Índice de Percepção de Corrupção (IPC) & Transparency International (2010-14) \\
\hline $\begin{array}{r}\text { Corrupção generalizada do } \\
\text { país receptor }\end{array}$ & $\begin{array}{l}\text { Média das respostas aos cinco componentes da seguinte pergunta: “No } \\
\text { seu país, é frequente as empresas terem que fazer pagamentos adicionais } \\
\text { não documentados ou subornos relativos a (a) importações e exportações; } \\
\text { (b) serviços de utilidade pública; (c) pagamento de impostos; (d) atribuição } \\
\text { de contratos públicos e licenças; (e) obtenção de favorecimentos } \\
\text { judiciais?” (tradução nossa). A escala de } 1 \text { (muito frequente) a } 7 \text { (nunca } \\
\text { ocorrem). Os valores foram invertidos para melhor interpretação. }\end{array}$ & Global Competitiveness Report (2010-14) \\
\hline Distância da corrupção & $\begin{array}{l}\text { Variável dicotômica que assume o valor de } 1 \text { quando a corrupção do país } \\
\text { investidor é menor do que a do país receptor, e } 0 \text { quando a corrupção do } \\
\text { país investidor é maior do que a do país receptor do investimento. }\end{array}$ & Transparency International (2010-2014) \\
\hline \multicolumn{3}{|c|}{ Variáveis de controle } \\
\hline Burocracia do país receptor & Tempo necessário para criar um novo negócio, em dias. & Global Competitiveness Report (2010-14) \\
\hline $\begin{array}{l}\text { Distância geográfica entre } \\
\text { país investidor-receptor }\end{array}$ & $\begin{array}{l}\text { Distância física em quilómetros entre as capitais dos pares de países } \\
\text { investidores e receptores }\end{array}$ & $\begin{array}{l}\text { Centre d'Etudes Prospectives et } \\
\text { d'Informations Internationales (CEPII) }\end{array}$ \\
\hline PIB país receptor & Logaritmo natural do valor do PIB, em milhões de dólares & $\begin{array}{l}\text { World Development Indicators, do Banco } \\
\text { Mundial (2010-14) }\end{array}$ \\
\hline $\begin{array}{r}\text { Presença de IDE no país } \\
\text { receptor }\end{array}$ & $\begin{array}{l}\text { Média ponderada das respostas à seguinte pergunta: “No seu país, quão } \\
\text { predominante é a posse de empresas por parte de capital estrangeiro?" } \\
\text { (tradução nossa). A escala das respostas varia entre o } 1 \text { (extremamente } \\
\text { raro) e o } 7 \text { (altamente predominante). }\end{array}$ & Global Competitiveness Report (2010-14) \\
\hline Carga fiscal do país receptor & $\begin{array}{l}\text { Combinação da percentagem de impostos sobre o lucro, percentagem de } \\
\text { impostos sobre o trabalho e outros impostos. }\end{array}$ & Global Competitiveness Report (2010-14) \\
\hline
\end{tabular}

Fonte: Elaborado pelos autores

dos países receptores, disponíveis na base de dados World Development Indicators, do Banco Mundial. Um mercado também poderá ser mais atrativo se tiver investimento de outras EMNs, já que reduzem a incerteza quanto aos seus investimentos nesses países. (Campos \& Kinoshita, 2003). A variável presença de IDE no país receptor foi operacionalizada com a média ponderada das respostas à pergunta "No seu país, quão predominante é a posse de empresas por parte de capital estrangeiro?" (nossa tradução), disponível no Executive Opinion Survey do World Economic Forum e foram coletados a partir do Global Competitiveness Report. A escala das respostas varia entre o 1 (extremamente raro) e o 7 (altamente predominante). Por fim, a atratividade de um país receptor ao IDE pode também ser influenciada pela carga fiscal (Slamrod, 1990). A carga fiscal do país receptor foi operacionalizada através de uma combinação da percentagem de impostos sobre o lucro, percentagem de impostos sobre o trabalho e outros impostos, usando dados do Doing Business
Project, do Banco Mundial, disponíveis no Global Competitiveness Report.

\subsection{Procedimentos de análise}

Para examinar o impacto da corrupção arbitrária e generalizada no IDE e o efeito moderador da distância da corrupção, utilizamos o modelo estatístico de regressão Tobit. Esta especificação é adequada porque a variável dependente, o logaritmo natural do IDE, assume valores não negativos - ou seja, é censurada à esquerda (Cuervo-Cazurra, 2008). Dada a existência de variáveis logaritmizadas em ambos os lados da equação, este modelo é referido como sendo duplo-log (Wei, 2000).

\section{RESULTADOS}

A tabela 2 apresenta as estatísticas descritivas, média e desvio padrão, das variáveis e suas correlações. Foram testados os VIF (Variance Inflation Factor), para verificar possíveis problemas de 
Tab. 2

Estatísticas descritivas e matriz de correlações

\begin{tabular}{|c|c|c|c|c|c|c|c|c|c|c|}
\hline Variável & Média & $\begin{array}{l}\text { Desvio } \\
\text { Padrão }\end{array}$ & 1 & 2 & 3 & 4 & 5 & 6 & 7 & 8 \\
\hline 1. Influxo de IDE & 2.312 & 0.882 & 1.000 & & & & & & & \\
\hline 2. Corrupção arbitrária país receptor & 3.258 & 1.732 & -0.085 & 1.000 & & & & & & \\
\hline 3. Corupção generalizada do país receptor & 6.230 & 0.928 & $-0.143^{* *}$ & 0.031 & 1.000 & & & & & \\
\hline 4. Distância de corrupção & 0.850 & 0.359 & $.108^{*}$ & -0.061 & $0.359 * *$ & 1.000 & & & & \\
\hline 5. Burocracia do país receptor & 32.069 & 28.835 & $0.121^{* *}$ & $0.412 * *$ & $0.103^{*}$ & $0.098 *$ & 1.000 & & & \\
\hline $\begin{array}{l}\text { 6. Distância geográfica entre país } \\
\text { investidor-receptor }\end{array}$ & 6903.504 & 4174.965 & $0.100 *$ & -0.056 & $-0.133 * *$ & $0.205^{* *}$ & $0.182 * *$ & 1.000 & & \\
\hline 7. PIB país receptor & 10.996 & 0.696 & $0.645^{* *}$ & -0.043 & $-0.114 *$ & $0.170 * *$ & $0.303 * *$ & $0.379 * *$ & 1.000 & \\
\hline 8. Presença de IDE no país receptor & 4.860 & 0.745 & 0.078 & $0.104^{*}$ & $-0.650 * *$ & $-0.307^{* *}$ & $-0.263^{* *}$ & -0.012 & 0.071 & 1.000 \\
\hline 9. Carga fiscal do país receptor & 54.270 & 21.935 & $0.315^{* *}$ & 0.074 & $0.393 * *$ & $0.165 * *$ & $0.178 * *$ & 0.080 & $0.411^{* *}$ & $-0.251^{* *}$ \\
\hline
\end{tabular}

$* \mathrm{p}<0.1 ;{ }^{* *} \mathrm{p}<0.05 ; * * * \mathrm{p}<0.01$.

Fonte: Elaborado pelos autores

multicolinearidade das variáveis. Os testes não devolveram resultados significantes.

A tabela 3 apresenta os resultados da regressão para testar as hipóteses. 0 modelo 1 inclui apenas as variáveis de controle. Os modelos 2 a 5 testam as hipóteses e o modelo 6 é o modelo completo. 0 modelo 2 apresenta os resultados para o teste da hipótese 1 sugerindo que a corrupção arbitrária nos países receptores teria uma influência negativa nos influxos de IDE. O coeficiente resultante não é significante estatisticamente, pelo que $\mathrm{H} 1$ não foi confirmada. Este resultado não corrobora a posição da literatura sobre a importância da corrupção arbitrária (Cuervo-Cazurra, 2008), que afirma que a corrupção arbitrária tem um impacto negativo na captação de IDE. Talvez os investidores não consigam planear de antemão os custos ou não consigam calcular a probabilidade de lhes serem solicitados subornos nos países onde intencionam investir; o que pode explicar, pelo menos em parte, a não confirmação da hipótese avançada.

O modelo 3 testa a hipótese 2 propondo uma influência negativa da corrupção generalizada nos influxos de IDE. A hipótese é confirmada com um coeficiente negativo e estatisticamente significante $(\beta=-0,233, p<0,01)$ nos influxos de IDE. Assim, quanto maior forem os níveis de corrupção generalizada, menor é o influxo de IDE. Possivelmente, o custo expectável relativo aos pagamentos adicionais não documentados para que determinada transação ocorra, assim como a certeza da recorrência dos mesmos, demove as intenções de investimento das EMNs (Ferreira et al., 2016; Cuervo-Cazurra, 2008).

O modelo 4 testa $\mathrm{H} 3$ que propõe um efeito moderador da distância de corrupção entre o país

Tab. 3

Resultados da regressão

\begin{tabular}{|c|c|c|c|c|c|c|}
\hline & Model 1 & Model 2 & Model 3 & Model 4 & Model 5 & Model 6 \\
\hline Corrupção arbitrária país receptor & & -0.028 & & $-0.096 * *$ & & -0.065 \\
\hline Corrupção generalizada país receptor & & & $-0.233 * * *$ & & $-0.258 * * *$ & $-0.215 * *$ \\
\hline Distância da corrupção & & & & -0.212 & 0.350 & 0.320 \\
\hline Corrupção arbitrária país receptor * distância da corrupção & & & & $0.0863^{* *}$ & & 0.057 \\
\hline Corrupção generalizada país receptor * distância da corrupção & & & & & -0.024 & -0.054 \\
\hline Burocracia do país receptor de IDE & $-0.002 * * *$ & 0.001 & $-4.957 * * *$ & -0.001 & $-0.003^{* * *}$ & -0.002 \\
\hline Distância geográfica entre país investidor-receptor & $-3.425 * * *$ & $-3.488^{* * *}$ & $-3.768 * * *$ & $-3.704 * * *$ & $-4.095 * * *$ & $-4.169 * * *$ \\
\hline Presença de IDE no país receptor & 0.042 & 0.064 & $-0.153 * *$ & 0.092 & $-0.145^{*}$ & -0.107 \\
\hline Carga fiscal no país receptor & $0.003 *$ & $0.003^{* *}$ & $0.005^{* * *}$ & $0.003^{* *}$ & $0.006^{* * *}$ & $0.006^{* * *}$ \\
\hline N & 473 & 473 & 473 & 473 & 473 & 473 \\
\hline$x^{2}$ & $377.561^{* * *}$ & $381.069 * * *$ & $406.413^{* * *}$ & $390.227 * * *$ & $415.797 * * *$ & $421.118^{* * *}$ \\
\hline Log. Verosimilhança & -483.948 & -483.026 & -476.159 & -480.559 & -473.743 & -472.389 \\
\hline Critério de Aikake & 981.896 & 982.052 & 968.319 & 981.117 & 967.486 & 968.779 \\
\hline
\end{tabular}

Variável dependente: Log IDE país receptor

Nota: ${ }^{*} p<0.1 ;{ }^{* *} p<0.05 ;{ }^{* * *} p<0.01$.

Fonte: Elaborado pelos autores 
investidor e o país receptor na relação entre a corrupção arbitrária e os influxos do IDE. O coeficiente é estatisticamente significante $(\beta=0,083$, $p<0,05)$, confirmando a hipótese. O resultado do termo de interação indica que o impacto negativo da corrupção é atenuado com a distância da corrupção. Ou seja, quanto maior a distância de corrupção menor a sensibilidade do IDE à corrupção arbitrária.

Por último, o modelo 5 testa o efeito moderador da distância de corrupção entre o país investidor e o país receptor na relação entre a corrupção generalizada e o IDE. O resultado não é estatisticamente significante para confirmar a hipótese proposta. A distância da corrupção implicaria esforços e custos adicionais aos já conhecidos da corrupção generalizada, que tornariam a operação mais incerta e arriscada. Contudo, neste estudo não foi possível verificar a ideia de que a diferença entre os níveis de corrupção dos países investidores e os países receptores de IDE acentuaria a relação já negativa entre os influxos de IDE e a corrupção generalizada; o que confirma Habib e Zurawicki (2002).

\section{DISCUSSÃO E COMENTÁRIOS FINAIS}

Neste estudo contribuímos para a literatura sobre o impacto da corrupção nos influxos de IDE fazendo duas extensões: por um lado, distinguindo o tipo de corrupção em arbitrária e generalizada, e por outro, escrutinando a distância de corrupção entre países investidores e receptores. Ou seja, propomos que para entender como os níveis de corrupção podem alterar a atratividade dos países e as decisões de realizar investimento pelas multinacionais, mas, também, que precisamos atender à distância de corrupção. O estudo estatístico foi realizado ao nível do país, com dados para países da América Latina. Este estudo estende, assim, sobre a literatura existente sobre os tipos de corrupção (ex., Uhlenbruck et. al., 2006; Cuervo-Cazurra, 2008) e sobre os estudos sobre distância de corrupção (Godinez \& Liu, 2015).

A maioria da pesquisa existente conclui que a corrupção é, efetivamente, desencorajadora do investimento estrangeiro (Judge et al., 2011). No entanto, o nosso estudo não corrobora completamente com resultados de pesquisas anteriores. Pelo menos em parte a divergência de resultados pode dever-se a considerarmos não a corrupção com uma dimensão única mas sim distinguirmos o tipo de corrupção. Os resultados, sobre os influxos de IDE na América Latina, provenientes de 27 países, revelaram que níveis superiores de corrupção generalizada reduzem a capacidade de atração de IDE. Isto é coerente com a maioria da pesquisa existente (ver, por exemplo, Rodriguez et al., 2005). No entanto, não identificámos um efeito significante entre corrupção arbitrária e os influxos de IDE, contrariamente ao proposto por Uhlenbruck et. al. (2006) e CuervoCazurra (2008). Aparentemente, as empresas que investem em países da América Latina não são dissuadidas pela arbitrariedade da corrupção. Uma possível explicação é que este tipo de corrupção já é esperado pelas empresas que não conseguem estimar o real impacto desta forma de corrupção sobre as suas operações exatamente devido ao seu carácter aleatório e discriminativo. Ou seja, talvez exista, no contexto da América Latina, uma dificuldade acrescida de avaliar, compreender e identificar a corrupção arbitrária, por comparação à corrupção generalizada.

O nosso estudo, porém, também indica que necessitamos analisar a distância de corrupção. Ao investigar o efeito moderador da distância da corrupção na relação entre os influxos de IDE e a corrupção, arbitrária e generalizada, encontramos resultados díspares entre os tipos de corrupção elencados. Se por um lado não existe um efeito estatisticamente significante na relação entre corrupção generalizada e os influxos de IDE, já na relação entre a corrupção arbitrária e O IDE, a distância da corrupção age como um efeito atenuador. Significa dizer que os investidores, na presença de distância da corrupção, ainda que receiem os efeitos da corrupção no seio das suas organizações, não se deterão tanto perante níveis de corrupção arbitrária existentes nos países receptores de IDE. O resultado vai de encontro e reforça a afirmação aquando da análise do impacto da corrupção arbitrária no IDE, de uma forma isolada. Isto é, aparentemente os países que investem na América Latina poderão não ser dissuadidos pela arbitrariedade da corrupção. Este menor receio dever-se-á ao facto de a escassa familiaridade institucional existente nos países receptores de IDE, por comparação aos países investidores, não acrescentar incerteza perante um mercado já de si incerto (Cuervo-Cazurra, 2008). Outra hipótese explicativa seria o facto de a atratividade e lucro expectável das operações internacionais justificarem 
o risco da corrupção (Bardhan, 1997; Huntington, 1968). Já o investimento perante a corrupção generalizada parece não sofrer nenhum efeito atenuador ou potenciador por parte da distância da corrupção. Talvez a força dissuasora da corrupção generalizada justifique a ausência de moderações significantes.

Uma dimensão que pode ser pertinente no estudo dos efeitos da corrupção, possivelmente tal como outras ineficiências institucionais, é o sentido da corrupção (Godinez \& Liu, 2015) e a possibilidade de as empresas desenvolverem o que se pode designar por uma corruption capability. Ou seja, que as empresas podem desenvolver no seu mercado doméstico uma competência em lidar com a corrupção. Cuervo-Cazurra e Genc (2008) referem-se a esta como sendo uma vantagem de posse (na tipologia OLI de Dunning, uma ownership advantage). Nesta medida, seria relevante entender se e como as empresas de países mais corruptos conseguem usar esta competência na sua expansão internacional.

\subsection{Limitações e sugestões de pesquisa futura}

Este estudo tem limitações. Primeiro, dado o carácter complexo e multifacetado da corrupção é difícil uma mensuração precisa pelas dificuldades de conseguir a participação de gestores no estudo. Assim, a utilização de dados secundários e gerais sobre a percepção de corrupção não permite nem identificar as diferentes facetas que a corrupção pode assumir, nem efetivamente os reais níveis de corrupção existentes. Estudos futuros, usando metodologias qualitativas ou quantitativas e em especial baseados em questionários poderão lançar luz adicional sobre o fenômeno da corrupção.

A utilização de dados secundários, ainda que de fontes conceituadas, impõe outras limitações. O número de observações foi baseado num grupo relativamente de países receptores; obrigando a considerar um período de cinco anos consecutivos. No entanto, importa notar que não efetuamos análises longitudinais, dado que as hipóteses não preveem efeitos ao longo do tempo. Ainda assim, poderá ser relevante entender como as melhorias no ambiente institucional, onde se inclui a corrupção, podem influenciar positivamente a capacidade de os países atraírem investimentos estrangeiros.

É relevante notar que a maioria dos influxos de IDE para a América Latina provêm de países institucionalmente mais desenvolvidos e com menores níveis de corrupção. Ou seja, a análise pode ter algum viés originado por investimentos de países menos corruptos para países menos corruptos. Será, no entanto, interessante observar em maior detalhe o efeito inverso, ou seja, quando os países investidores têm maiores níveis de corrupção que os países receptores do investimento.

Embora exista já um conhecimento acumulado substancial sobre o efeito da corrupção, há, ainda, muita pesquisa para ser realizada. Por exemplo, pesquisas futuras podem analisar as consequências económicas da corrupção, tais como o seu efeito sobre a composição do IDE (Smarzynska \& Wei, 2000). Empresas que têm uma orientação para o mercado (o que Dunning designou por market seeking) podem estar sujeitas a níveis distintos de corrupção das empresas que buscam acessar recursos estratégicos (strategic asset seeking). Estas análises também envolvem escrutinar os trade-offs de custos e benefícios de encetar corrupção (Ferreira et al., 2016).

Em conclusão, os fatores institucionais são relevantes para as decisões de investimento das EMNs. Essa importância é maior quando analisamos países em desenvolvimento e da América Latina, uma vez que a imaturidade institucional aumenta os custos de transação e o nível de risco (Ali et al., 2010). A corrupção provém de insuficiências institucionais e gera incerteza nas ações de internacionalização. A análise dos influxos de IDE para os países da América Latina permitiu concluir que a distância da corrupção ameniza o efeito negativo da corrupção arbitrária do país receptor nos influxos de IDE. Por outro lado, independentemente do sentido do investimento, só a corrupção generalizada dos países receptores tem um efeito negativo sobre os IDE sugerindo que é a corrupção organizada e recorrente - ou generalizada - que demove os influxos de IDE.

\section{REFERÊNCIAS}

- $\quad$ Ali, F., Fiess, N., \& MacDonald, R. (2010). Do institutions matter for foreign direct investment? Open Economies Review, 21(2), 201-219.

- Bardhan, P. (1997). Corruption and development: A review of the issues. Journal of Economic Literature, 35(3), 1320-1346.

- Bénassy-Quéré, A., Coupet, M., \& Mayer, T. (2007). Institutional determinants of foreign direct investment. The World Economy, 30(5), 764-782.

- Bevan, A., Estrin, S., \& Meyer, K. (2004). Foreign investment location and institutional development in 
transition economies. International Business Review, 13(1), 43-64.

- Bogmans, C., \& Jong, E. (2011). Does corruption discourage international trade? European Journal of Political Economy, 27(2), 385-398.

- Buckley, P., Clegg, J., Liu, X., Voss, H., \& Zheng, P. (2007). The determinants of Chinese outward foreign direct investment. Journal of International Business Studies, 38(4), 499- 518.

- Campos, N., \& Kinoshita, Y. (2003). Why does FDI go where it goes? New evidence from the transition economies, WP 02/228, IMF Institute.

- Chao, M. C. H., \& Kumar, V. (2010). The impact of institutional distance on the international diversityperformance relationship. Journal of World Business, 45(1), 93-103.

- Cuervo-Cazurra, A. (2006). Who cares about corruption? Journal of International Business Studies, 37(6), 807-822.

- Cuervo-Cazurra, A. (2008). Better the devil you don't know: Types of corruption and FDI in transition economies. Journal of International Management, 14(1), 12-27.

- Cuervo-Cazurra, A. (2008b). The effectiveness of laws against bribery abroad. Journal of International Business Studies, 39(4), 634-651.

- Cuervo-Cazurra, A., \& Dau, L. (2009). Promarket reforms and firm profitability in developing countries. Academy of Management Journal, 52(6), 1348-1368.

- Daude, C., \& Stein, E. (2007). The quality of institutions and foreign direct investment. Economics \& Politics, 19(3), 317-344.

- Doh, J., Rodriguez, P., Uhlenbruck, K., Collins, J., \& Eden, L. (2003). Coping with corruption in foreign markets. Academy of Management Executive, 17(3), 114-127.

- Driffield, N., Jones, C., \& Crotty, J. (2013). International business research and risky investments, an analysis of FDI in conflict zones. International Business Review, 22(1), 140-155.

- Eden, L., \& Miller, S. (2004). Distance matters: Liability of foreignness, institutional distance and ownership strategy. Advances in International Management, 187-221.

- Egger, P., \& Winner, H. (2005). Evidence on corruption as an incentive for foreign direct investment. European Journal of Political Economy, 21(4), 932952.

- Elliot, K. (Ed.). (1997). Corruption and the global economy. Washington, DC: Institute for International Economics.

- $\quad$ Ferreira, M., Carreira, H., Li, D., \& Serra, F. (2016). O efeito moderador da corrupção do país de origem sobre a capacidade do país receptor de atrair IED. Brazilian Business Review, 13(4), 98-123.
- Galang, R. (2012). Victim or victimizer: Firm responses to government corruption. Journal of Management Studies, 49(2), 429-462.

- Gelbuda, M., Meyer, K., \& Delios, A. (2008). International business and institutional development in Central and Eastern Europe. Journal of International Management, 14(1), 1-11.

- Globerman, S., \& Shapiro, D. (1999). The impact of government policies on foreign direct investment: The Canadian experience. Journal of International Business Studies, 30(3), 513-532.

- Globerman, S., \& Shapiro, D. (2003). Governance infrastructure and US foreign direct investment. Journal of International Business Studies, 34(1), 19-39.

- Godinez, J., \& Liu, L. (2015). Corruption distance and FDI flows into Latin America. International Business Review, 24(1), 33-42.

- Habib, M., \& Zurawicki, L. (2002). Corruption and foreign direct investment. Journal of International Business Studies, 33(2), 291-307.

- Hernández, V., Nieto, M. (2015). The effect of the magnitude and direction of institutional distance on the choice of international entry modes. Journal of World Business, 50(1), 122-132.

- Hines, J. (1995). Forbidden payment: Foreign bribery and American business after 1977. (No. w5266). National Bureau of Economic Research.

- Huntington, S. (1968). Political order in changing societies. New Haven: Yale University Press.

- Jeong, Y. \& Weiner, R. (2012). Who bribes? Evidence from the United Nations' oil-for-food program. Strategic Management Journal, 33(12), 1363-1383.

- Judge, W., McNatt, B. \& Xu, W. (2011). The antecedents and effects of national corruption: $A$ meta-analysis. Journal of World Business, 46, 93-103.

- Karnani, A. (2007). Doing well by doing good - case study: "Fair \& Lovely" whitening cream. Strategic Management Journal, 28(13), 1351-1357.

- Kinoshita, Y. \& Campos, N. (2004). Estimating the determinants of foreign direct investment inflows: How important are sampling and omitted variable biases? The Bank of Finland Institute for Transition Economies, Discussion Paper No. 10.

- LaPalombara, J. (1994). Structural and institutional aspects of corruption. Social Research, 61(2), 325-350.

- Leff, N. (1964). Economic development through bureaucratic corruption. American Behavioral Scientist, 8(3), 8-14.

- Lui, F. (1985). An equilibrium queuing model of bribery. Journal of Political Economy, 93(4), 760-781.

- Méon, P., \& Sekkat, K. (2005). Does corruption grease or sand the wheels of growth? Public Choice, 122(1), 69-97. 
- Meyer, K. (2001). Institutions, transaction costs, and entry mode choice in Eastern Europe. Journal of International Business Studies, 32(2), 357-367.

- Mudambi, R., \& Navarra, P. (2002). Institutions and international business: A theoretical overview. International Business Review, 11(6), 635-646.

- Pajunen, K. (2008). Institutions and inflows of foreign direct investment: A fuzzy-set analysis. Journal of International Business Studies, 39(4), 652-669.

- Peng, M. (2003). Institutional transitions and strategic choices. Academy of Management Review, 28(2), 275.

- $\quad$ Peng, M., \& Heath, P. (1996). The growth of the firm in planned economies in transition: Institutions, organizations, and strategic choice. Academy of Management Review, 21(2), 492-528.

- Rodriguez, P., Uhlenbruck, K., \& Eden, L. (2005). Government corruption and the entry strategies of multinationals. Academy of Management Review, 30(2), 383-396.

- $\quad$ Shleifer, A., \& Vishny. R. (1993). Corruption. Quarterly Journal of Economics, 108(3), 599-617.

- Smarzynska, B., \& Wei, S. (2000). Corruption and composition of foreign direct investment: Firm-level evidence. National bureau of economic research, w7969.
- Transparency International (2007). Global Corruption Report. Cambridge, MA: Cambridge University Press.

- Uhlenbruck, K., Rodriguez, P., Doh, J., \& Eden, L. (2006). The impact of corruption on entry strategy: Evidence from telecommunication projects in emerging economies. Organization Science, 17(3), 402-414.

- Voyer, P., \& Beamish, P. (2004). The effect of corruption on Japanese foreign direct investment. Journal of Business Ethics, 50(3), 211-224.

- Wei, S. (1998). Corruption in economic development: Beneficial grease, minor annoyance, or major obstacle? World Bank Policy Research Working Paper, 2048.

- Wei, S-J. (2000). How taxing is corruption on international investors? Review of Economics and Statistics, 82(1), 1-11.

- Wernick, D., Haar, J., \& Singh, S. (2009). Do governing institutions affect foreign direct investment inflows? New evidence from emerging economies. International Journal of Economics and Business Research, 1(3), 317-332.

- Zeghni, S., \& Fabry, N. (2009). Inward FDI in the transitional countries of South Eastern Europe: A quest of institution-based attractiveness. Eastern Journal of European Studies, 1(2), 77-91

\section{SOBRE OS AUTORES}

- Manuel Aníbal Silva Portugal Vasconcelos Ferreira é Professor de Estratégia e Negócios internacionais. Doutor em Gestão pela Universidade de Utah, EUA. Pós doutorado pela Universidade de São Paulo. Interesses de investigação estão numa perspetiva institucional em economias emergentes, incluindo o papel do governo, grupos econômico e as estratégias de multinacionais emergentes, especialmente na América Latina. E-mail: manuel.portugal.ferreira@gmail.com

- Daniel Mendes Pessegueiro é Mestre em negócios internacionais. Pesquisador no globADVANTAGE. Consultor de gestão e tecnologias de informação. Interesse de pesquisa em ambiente internacional de negócios e seu impacto na internacionalização das empresas.E-mail: dpessegueiro@hotmail.com

- Nuno Rosa Reis é Professor de Estratégia e Negócios Internacionais. Doutorado em Gestão pela Universidade de Coimbra. Os seus interesses de pesquisa incluem o impacto das diferenças institucionais nas ações e desempenho de empresas multinacionais.E-mail: nuno.m.reis@ipleiria.pt

- Cláudia Sofia Frias Pinto é Professora no Programa de Mestrado e Doutorado em Administração da Unoesc. Leciona disciplinas nas áreas de Estratégia e Negócios Internacionais. Doutorada em Administração de Empresas pela FGV/EAESP. A sua pesquisa se centra na estratégia e comportamento de empresas multinacionais de países emergentes e aquisições internacionais de empresas. E-mail: claudia.frias.pinto@gmail.com 


\title{
The influence of arbitrary and pervasive corruption on FDI inflows and the moderating effect of corruption distance: evidence from Latin America
}

\author{
Daniel Mendes Pessegueiro ${ }^{\mathrm{AB}}$, Manuel Aníbal Silva Portugal Vasconcelos Ferreira ${ }^{\mathrm{ABC}}$, \\ Nuno Rosa Reis ${ }^{A B}$, and Cláudia Sofia Frias Pinto ${ }^{C}$ \\ ${ }^{A}$ Escola Superior de Tecnologia e Gestão, Instituto Politécnico de Leiria, ESTG-IPL, Leiria, Portugal \\ ${ }^{B}$ Centre of Applied Research in Management and Economics, CARME, Leiria, Portugal \\ 'Universidade Nove de Julho, PPGA, UNINOVE, São Paulo, SP, Brazil \\ DUniversidade do Oeste de Santa Catarina, PPGA, UNOESC, Chapecó, SC, Brazil
}

\section{ARTICLE DETAILS \\ Article history: \\ Received: August 08, 2017 \\ Reviewed: September 11, 2017 \\ Accepted December 07, 2017 \\ Available online April 10, 2018 \\ Double Blind Review System \\ Scientifc Editor \\ Raquel Moutinho}

\section{Keywords:}

Arbitrary corruption

Pervasive corruption

Corruption distance

Foreign direct investment

Latin America
ABSTRACT

There is no consensus in the literature on the negative effect of corruption on countries' ability to attract foreign direct investment (FDI). Some countries simultaneously have high levels of corruption and FDI flows. In this study, we distinguish the effect of two types of corruption - arbitrary and pervasive - and the moderating role of corruption distance between the investor and host country on the ability to attract FDI. In an empirical study of FDI flows into Latin American countries, the results show that high pervasive corruption reduces the attractiveness of FDI and that corruption distance attenuates the negative effect of arbitrary corruption on FDI. The study contributes to the research on the effects of corruption and particularly to understanding the differentiated effects of the types of corruption and of corruption distance on FDI flows.

(C) 2018 Internext | ESPM. All rights reserved!

Para citar este artigo:

Pessegueiro, D. M.; Ferreira, M. A. S. P. V.; Reis, N. R. e Pinto, C. S. F. (2018) O impacto da corrupção arbitrária e generalizada nos influxos de IDE e o efeito moderador da distância de corrupção: Evidências da América Latina. Internext - Revista Eletrônica de Negócios Internacionais, 13 (1), 50-62. DOI: http://dx.doi.org/10.18568/1980-4865.13150-62

Para acessar este artigo: http://dx.doi.org/ 10.18568/1980-4865.13150-62 